\title{
Rituais de consumo de cannabis por usuários na fronteira entre o Brasil e o Uruguai
}

Cannabis consumption rites by users at the border between Brazil and Uruguay

Rituales de consumo de cannabis por usuarios en la frontera entre el Brasil y el Uruguay

\section{Diogo Henrique Tavares ${ }^{\mathrm{I}}$, Beatriz Franchini ${ }^{\mathrm{II}}$, Heitor Silva Biondi' ${ }^{\mathrm{II}}$, Vanda Maria da Rosa Jardim $^{\mathrm{IV}}$, Cândida Garcia Sinott Silveira Rodrigues ${ }^{\mathrm{v}}$, Paola de Oliveira CamargovI}

\begin{abstract}
Resumo: Objetivo: conhecer os rituais de consumo de Cannabis Sativa por usuários em uma cidade brasileira que faz fronteira com o Uruguai. Método: estudo qualitativo, exploratório e descritivo. Os dados foram coletados com 11 usuários de Cannabis Sativa por meio de entrevista semiestruturada, em outubro de 2016 e submetidos a Análise de Conteúdo. Resultados: os rituais de consumo revelam-se influenciados por elementos socioculturais, econômicos e políticos, potencializados pelas políticas divergentes referentes ao consumo de Cannabis desses países. Estes rituais perpassam a aquisição, periodicidade, quantidade, métodos, locais, socialização e sensações experienciadas pelos usuários. Conclusão: os rituais estão atrelados às características do usuário, grupos sociais e do território. Destaca-se as influências conflitantes das políticas públicas existentes entre os dois países, marcadas pela regulamentação da Cannabis no Uruguai, o que fomenta mudanças que estão, continuamente, acontecendo nos rituais de consumo, sendo necessário acompanhar as transformações sociais neste espaço.

Descritores: Cannabis; Áreas de fronteira; Comportamento ritualístico; Drogas ilícitas
\end{abstract}

Abstract: Aim: to know the rituals of consumption of Cannabis Sativa by users in a Brazilian city bordering Uruguay. Method: qualitative, exploratory and descriptive study. The data were collected with 11 users of Cannabis Sativa through semi structured interview, in October 2016 and submitted to Content Analysis. Results: consumption rituals are influenced by sociocultural, economic and political elements, potentialized by the

\footnotetext{
${ }^{\text {I }}$ Enfermeiro, Professor Substituto da Faculdade de Enfermagem, Doutorando em Enfermagem. Mestre em Ciências, Universidade Federal de Pelotas, Pelotas, Rio Grande do Sul, Brasil, enf.diogotavares@gmail.com ORCID 0000-0002-0961-6421

II Enfermeira, Professora da Faculdade de Enfermagem, Doutora em Ciências, Universidade Federal de Pelotas, Pelotas, Rio Grande do Sul, Brasil, beatrizfranchini@hotmail.com ORCID 0001-7022-1552

${ }^{\text {III }}$ Enfermeiro. Doutorando em Enfermagem. Hospital Universitário Dr. Miguel Riet Correa Jr. Universidade Federal do Rio Grande, Integrante do Grupo de Pesquisa Viver Mulher. Rio Grande, Rio Grande do Sul, Brasil. E-mail: enf.heitor@gmail.com ORCID 0000-0002-7175-9538

IV Enfermeira, Professora da Faculdade de Enfermagem, Doutora em enfermagem, Universidade Federal de Pelotas, Pelotas, Rio Grande do Sul, Brasil, vandamrjardim@gmail.com ORCID 0000-0001-8320-4321

v Enfermeira, Mestre em Ciências, Universidade Federal de Pelotas, Universidade Federal de Pelotas, Pelotas, Rio Grande do Sul, Brasil, candidasinott@hotmail.com ORCID 0000-0001-7719-0621

VI Pedagoga, Mestre em Ciências, Universidade Federal de Pelotas, Pelotas, Rio Grande do Sul, Brasil, paolacamargo01@hotmail.com ORCID 0000-0002-9169-7602
} 
divergent policies regarding cannabis consumption in these countries. These rituals pervade the acquisition, periodicity, quantity, methods, places, socialization and sensations experienced by the users. Conclusion: rituals are linked to the characteristics of the user, social groups and territory. The conflicting influences of the public policies existing between the two countries, marked by the regulation of Cannabis in Uruguay, are highlighted, which foments changes that are continually happening in the rituals of consumption. Hence, it is necessary to accompany the social transformations in this space.

Keywords: Cannabis; Border areas; Ritual behavior; Illicit drugs

Resumen: Objetivo: conocer los rituales del consumo de Cannabis Sativa de los usuarios en una ciudad brasileña que limita con Uruguay. Método: estudio cualitativo, exploratorio y descriptivo. Los datos fueron recolectados con 11 usuarios de Cannabis Sativa por medio de entrevista semiestructurada, en octubre de 2016 y sometidos a Análisis de Contenido. Resultados: los rituales se revelan influenciados por elementos socioculturales, económicos y políticos, potenciados por las políticas divergentes referentes al consumo de Cannabis de esos países. Esos rituales están relacionados a la adquisición, periodicidad, cantidad, métodos, locales, socialización y sensaciones experimentadas por los usuarios. Conclusión: los rituales están vinculados a las características del usuario, de los grupos sociales y del territorio. Se destacan las influencias conflictivas de las políticas públicas existentes entre los dos países señaladas por la reglamentación del Cannabis en Uruguay, lo que alienta cambios que están continuamente sucediendo en los rituales, siendo necesario acompañar las transformaciones sociales en este espacio.

Descriptores: Cannabis; Áreas de frontera; Comportamiento ritual; Drogas ilícitas

\section{Introdução}

O consumo de substâncias psicoativas (SPA), popularmente mencionado como uso de “drogas”, sendo consideradas lícitas o álcool e tabaco ou ilícitas a Cannabis Sativa, vem ganhando ampla discussão na atualidade, devido ao crescente uso problemático pelos usuários e a pouca eficiência das políticas proibicionistas. Nos países como o Canadá, Holanda, Estados Unidos e Uruguai já vêm sendo adotadas políticas públicas inovadoras que regulamentam o uso de algumas SPA. ${ }^{1}$

No Uruguai, país que faz fronteira com o Brasil, a SPA que deixou de compor o rol da ilegalidade foi a Cannabis Sativa, conhecida como maconha, considerada uma das mais consumidas em todo mundo. Neste país, todo o processo de plantio, porte e comércio desta substância foi regulamentado por meio da Lei 19.172, sancionada em dezembro de $2013 .{ }^{2}$

Esta conjectura traz ao consumo no Uruguai novas características: da ilegalidade à legalidade e da exclusão social do usuário, à inclusão social. Todavia, o ambiente onde há a 
3 | Tavares DH, Franchini B, Biondi HS, Jardim VMR, Rodrigues CGSS, Camargo PO

intersecção de políticas divergentes acerca do tema, como no caso da fronteira entre Brasil e Uruguai, possui particularidades, oriundas dos limites territoriais, políticos e paradigmáticos. Este território, além das interações mencionadas, é o espaço em que as pessoas de ambos os países interagem no dia-a-dia, seja no comércio ou nas questões culturais, obtendo uma identidade do povo da fronteira. ${ }^{3}$

Neste ambiente de contrastes políticos, o consumo de Cannabis ocorre de maneira singular, materializando-se em um ritual de consumo com características e dinâmicas ímpares. Os rituais são compreendidos enquanto eventos sociais de um grupo que sofrem influências de diversos contextos, dentre eles, os culturais e políticos, que se tornam mutáveis de acordo com a interação dos sujeitos envolvidos e destes elementos contextuais. ${ }^{4}$

Considerando que a fronteira é influenciada pela bidirecionalidade de políticas antagônicas, torna-se um cenário inexplorado de possibilidades no que se refere aos rituais de consumo de Cannabis Sativa. Assim sendo, tem-se como questão de pesquisa: como ocorrem os rituais de consumo de Cannabis Sativa por usuários na região da fronteira entre o Brasil e o Uruguai? Compreende-se o consumo como o conjunto de processos socioculturais realizados com vistas à apropriação e uso de um determinado produto e, que esta ação possui valor simbólico e determina os papeis exercidos pelos consumidores e os grupos sociais ao qual pertencem. ${ }^{5}$ E, como objetivo: conhecer os rituais de consumo de Cannabis Sativa por usuários em uma cidade brasileira que faz fronteira com o Uruguai.

\section{Método}

Trata-se de um recorte da pesquisa intitulada "Monitoramento e avaliação dos efeitos da nova política uruguaia de regulação do mercado de Cannabis sobre a saúde pública e as práticas de consumo de drogas na zona de fronteira entre Brasil e Uruguai", ${ }^{6}$ realizada nos seis municípios que fazem fronteira com esses países. 
Este recorte constitui-se dos resultados qualitativos obtidos em um município brasileiro que faz fronteira seca com o Uruguai. O estudo possui natureza exploratório descritiva, ${ }^{7}$ de modo a responder o objetivo proposto. Participaram 11 pessoas usuárias de Cannabis, sendo duas do sexo feminino e nove do sexo masculino, solteiros, com idades entre 26 anos à 60 anos, com predomínio de pessoas na terceira década de vida. Oito pessoas não haviam concluído o ensino fundamental, duas tinham a escolaridade fundamental completa e uma estava cursando faculdade. Foram incluídos, no estudo, pessoas usuárias de Cannabis de nacionalidade brasileira, com 18 anos ou mais.

A coleta de dados foi realizada por meio de entrevista semiestruturada, contendo a caracterização dos participantes e questões norteadoras abertas, abordando o consumo de Cannabis e os contextos que permeiam essa ação, as dinâmicas dos rituais, os aspectos que os influenciam. Para acesso aos participantes e coleta de dados, realizada em outubro de 2016, foi empregado o método não probabilístico denominado Bola de Neve. ${ }^{8} \mathrm{O}$ primeiro participante (informante-chave) foi indicado pelo Serviço de Saúde responsável pelo cuidado às pessoas que fazem uso problemático de SPA do município onde foi desenvolvido o estudo. Após a participação do mesmo, este indicou outros usuários, e os demais usuários indicaram outros participantes, efetivando assim o método proposto. As entrevistas foram realizadas no serviço de saúde mental, unidade básica de saúde, em espaços públicos, como praças e nas residências dos participantes.

Para garantir a fidedignidade das falas, as entrevistas foram gravadas, mediante a autorização dos participantes e a assinatura do Termo de Consentimento Livre e Esclarecido. Logo após, foram transcritas, iniciando-se imediatamente o processo de Análise de Conteúdo, ${ }^{9}$ que se compõe de três etapas: pré-análise; exploração do material; e tratamento dos resultados e interpretação. Utilizou-se como critério de encerramento da pesquisa o aparecimento de dados homogêneos de forma repetitiva, ou seja, quando houve a saturação de dados. Após o início da 
5 | Tavares DH, Franchini B, Biondi HS, Jardim VMR, Rodrigues CGSS, Camargo PO

saturação dos dados, buscou-se a participação de mais três usuários, para confirmar os achados e validar a saturação. ${ }^{10}$

A macropesquisa foi financiada pela Secretaria Nacional sobre Drogas do Ministério da Justiça (SENAD/MJ) e aprovada pela Comissão de Ética do Instituto de Pesquisa Aplicada (IPEA) através do Ofício $\mathrm{N}^{\circ} 13 / 2015$ e pelo Comitê de Ética e Pesquisa da Faculdade de Enfermagem (UFPel) sob o Protocolo 1.757.94/2016, sendo respeitado a Resolução ${ }^{11} 466 / 2012$ do Conselho Nacional de Saúde do Ministério da Saúde, que trata das diretrizes e normas para pesquisas envolvendo seres humanos. Para manter o anonimato dos participantes, os mesmos foram identificados pela letra "U”, referente a palavra usuário, seguida pela ordem da realização das entrevistas, por exemplo,U1.

\section{Resultados}

Dos diferentes elementos inter-relacionados e interpostos emergiu o constructo de rituais de consumo de Cannabis na região da fronteira, com particularidades influenciadas por aspectos socioculturais, econômicos e políticos, apresentados em cinco categorias:

\section{Região de fronteira e suas influências sobre a aquisição da droga}

A aquisição de Cannabis no Brasil e no Uruguai efetiva-se de maneira particular, influenciada pela dissonância das leis que regem o comércio desta substância nos dois países. Participantes revelam que a aquisição da Cannabis é realizada no lado brasileiro da fronteira. Tal ação relaciona-se com o fato de haver a formação de uma rede de relações entre usuários e traficantes para poder ter acesso à SPA ilícita. Revelam também, que o modo de aquisição pode ser por meio de terceiros, ou da busca direta aos traficantes:

para conseguir é fácil, só ter alguém que fume e convide a gente. (U2) eu ia direto na 'boca'[local de tráfico] comprar com traficante. (U4) é difícil de conseguir maconha nessa região, tu tem que conhecer alguém. ninguém vai falar porque ninguém sabe, só quem sabe é a pessoa que é amigo do traficante, alguma coisa assim e já te mostra onde é. Aí tu passa a saber, e pode mostrar para outro amigo seu. Só quem usa é que sabe. (U11) 
Falas expressaram que, no lado brasileiro, os meios para conseguir a substância são mais fáceis, embora o comércio seja ilegal. Para comprar essa substância no Brasil, o usuário precisa ir a locais desconhecidos ou espaços de vulnerabilidade social, nos quais, geralmente são zonas de tráfico de “drogas”, o que se processa de modo distinto no Uruguai, já que os usuários podem plantar em casa e existem pontos específicos para esse mercado sem outras substâncias psicoativas disponíveis:

para conseguir é simples, tu sai a perguntar no centro e tu consegue, em qualquer lugar. Aqui [no Brasil] tu te sente ruim porque tu vai entrar numa vila, mas no Uruguai é tudo mais tranquilo. Lá tu vai comprar maconha e tem um lugar só para comprar maconha, diferente daqui que tem o restante das drogas, que eu acho que facilita para se usar outras coisas. Porque tu vai para comprar uma coisa e já tem outra. É a mesma coisa que ir ao mercado para comprar uma coisa e olhar o cartaz de outro produto e acabar levando [...]. (U3)

com a legalização no Uruguai, o tráfico parou. Agora as pessoas plantam, não compram mais com o traficante. Não tem onde a gente [brasileiro] comprar no Uruguai. (U8)

\section{Socialização e ambientes de consumo}

A forma e o local de uso diferem entre os entrevistados, sendo expressos rituais de consumo de dois modos: em grupo e sozinho. Apesar de referirem que o efeito da substância pode ser o mesmo que há no consumo de modo isolado, outros usuários referem maior satisfação ao fazerem o uso acompanhado. Dos locais em que realizam o uso, foram citados espaços públicos como praças, ruas e espaços privados para sentirem-se mais seguros:

usava drogas com as 'parcerias', dentro de casa, mas eu não sinto mais vontade de usar. Só a maconha que, às vezes, me dá vontade, mas eu procuro não usar. Sozinha eu não fumo. Eu só fumo se tiver alguém comigo. [...] tenho um amigo que fuma comigo. (U1)

quando eu fumo, é sempre com 'parceria'. Usava na rua mesmo, quando passava alguém, a gente se escondia. Em casa, sozinho, nunca. Minha família não deixa. (U2) 
geralmente sozinho, é raro em grupo. Ali na praça do Uruguai, às vezes, tu chega ali e a galera já vem fumar. Aqui não, a coisa já 'embaça'[problemas com a polícia] um pouquinho. Uma coisa é tu fumar sozinho, outra coisa é tu dar a maconha para alguém. Nossa lei é muito ruim. [...]. (U3)

[...] das duas formas. A diferença é que em grupo dá mais alegria. Um conta uma piada, outro conta outra. Daí cada um já arruma uma namorada e já sai para o baile. E sozinho, a pessoa se chapa muito e termina apagando, fica onde está, dormindo, só vai se acordar depois que passar o efeito. Eu prefiro fazer em grupo. (U5)

\section{Práticas de uso}

Para a realização do ritual de uso, as falas demonstram unanimidade quanto à forma de usar a Cannabis e do material necessário. A substância preferida, em termos de qualidade, está relacionada com o alcance do efeito almejado com sua utilização, tendo destaque a Cannabis prensada (maior oferta no comércio ilegal brasileiro), a qual é preparada em forma de cigarros, com papel de seda. Para a preparação do cigarro com a Cannabis prensada, esta necessita ser “esmurrugada”, visto que sua apresentação é sólida com atributos desconhecidos, ou seja, solta, de forma que fique mais fácil de acomodá-la na seda para que a substância seja enrolada.

Normalmente, os cigarros artesanais de Cannabis são preparados com uma ou mais folhas de seda. A forma de usar a Cannabis ocorre conforme o efeito que se almeja, destacandose a importância de tragar a fumaça e fazer uma pausa prolongada da respiração para alcançar o efeito psicoativo de modo mais rápido e intenso, o chamado processo de "prensar" a fumaça:

eu fumo com seda, enrolo e fumo. Coloco duas sedas, divido a maconha porque é muito, dá para fazer três cigarros com a quantidade de uma compra. As melhores maconhas são aquelas fortes, mais 'emborrachadas' [prensadas] que tem que esfarelar. (U1)

fechava ela que nem cigarro normal, moí [esfarelava], tirava a sementinha do meio, jogava fora, só a folhinha e a raminha. Moía bem 'moidinha', dentro do próprio papelzinho, tinha que ser o papel de seda, não podia ser papel de fumo. Daí a gente puxa, traga a fumaça, tranca o nariz, e a fumaça 'sobe para a cabeça'. (U5)

\section{Quantidade e periodicidade de consumo}


As falas expressam que existem variações na quantidade de Cannabis consumida e que esta depende da disponibilidade da substância psicoativa. Observou-se que um mesmo cigarro de Cannabis pode ser usado em várias etapas, por exemplo, fumando uma parte, apagando e fumando o restante depois:

fumo uns dois 'baseados' por dia, em várias vezes. Diariamente, sete vezes por dia, um baseado em sete vezes, às vezes dois. Tu dá dois 'pegas' [inalação de fumaça] e já apaga. Coloca umas quatro vezes por dia, de manhã, antes do almoço, depois do almoço, antes de dormir. Depois do almoço porque ela é digestiva, e relaxante. Uso uns dois gramas por dia, depende: dois gramas de 'prensado' é uma 'coisinha', dois gramas de "florão"[Cannabis sem misturas] éoutra.(U3)

depende da quantia que se tem. Se tiver bastante, fumo bastante. Se não tiver, não fumo. (U6)

As falas mostram que os entrevistados conseguem permanecer por períodos longos sem fazer o uso de Cannabis, variando de meses, até anos. Também foi identificado que o usuário dessa substância não desenvolve a fissura:

eu tinha 28 anos quando eu parei de usar frequentemente. $O$ máximo de tempo que eu já fiquei foram quatro anos sem usar. Se eu não quiser mais, eu não fumo. (U1)

a maconha, já fiquei 2 anos direto sem fumar. Há um mês não faço o uso. (U10)

\section{Sensações}

Múltiplas sensações e efeitos são atribuídos pelos participantes ao uso de Cannabis, variando de pessoa para pessoa. Nos relatos foram expressados efeitos como: ansiolíticos, antidepressivos, de relaxamento e de sensações calmantes. Além destes, foi relatado o aumento do apetite, bem como alterações em relação à libido sexual. O aspecto negativo mencionado foi a confusão mental:

[...] eu começo a 'ratear'[ficar confuso]. (U1)

[...] não tem remédio que te deixa mais calmo que a maconha, ela deixa calmo. Eu sinto tudo, a maconha muda totalmente, o sexo é super atraente, tu fica com mais potência, causa maior potência sexual. Eu acabo tendo mais vontade no sexo e fica bem melhor. Eu fico mais alegre, droga que dá mais alegria igual a maconha, não tem. (U6) 
9 | Tavares DH, Franchini B, Biondi HS, Jardim VMR, Rodrigues CGSS, Camargo PO

eu acho que fico mais [...] Fico mais alegre também.(U7)

me ajuda a dormir e a comer muito.(U9)

\section{Discussão}

O contexto sociocultural fronteiriço e o consumo da Cannabis revelam-se preditivos a vivência ritualística para usuários de Cannabis. Como aponta a literatura, ${ }^{12}$ o ritual de consumo perpassa padrões de comportamentos estabelecidos pelos usuários, abarcando os métodos de aquisição da droga, seleção do meio físico e social onde ocorre o uso, as formas como este se processa, sua periodicidade, a quantidade consumida, as sensações e atividades empreendidas sob seu efeito, a associação entre substâncias e as maneiras de evitar consequências danosas.

A heterogeneidade em relação ao acesso à substância parece ser influenciada pelos aspectos ligados a ilegalidade e criminalização da venda e do consumo. Tal fato demonstra que o acesso é facilitado pelas redes informais de socialização existentes entre os usuários. Ao pertencer a uma rede, o usuário passa a ter livre acesso aos ambientes de comercialização ilegal. Todavia, enquanto não faz parte de uma rede, o usuário acaba por ter dificuldade de acesso aos pontos do comércio ilegal de substâncias psicoativas.

Um estudo desenvolvido nas cidades de São Paulo e Salvador, ${ }^{13}$ revela a importância da rede social formada pelos usuários, abrangendo seu primeiro contato com a Cannabis, que se dá por meio de amigos e/ou familiares e, posteriormente, na realização e manutenção do consumo. Esta rede é considerada eficaz, devido à dependência que o usuário desenvolve em relação a ela, no que tange a aquisição e uso da Cannabis. A rede interfere no controle do uso, sendo um modo de redução de danos, ${ }^{14}$ considerando que nem sempre os elementos que compõe esta rede estão disponíveis para a pessoa conseguir consumir, o que pode inviabilizar o uso quando não se está em companhia destes.

Mesmo diante das severas leis que próibem a comercialização e consumo da Cannabis no Brasil, vislumbra-se maior facilidade em realizar a aquisição da substância do lado brasileiro da fronteira. Tal aspecto revela a ineficiência dos serviços de segurança pública em garantir a 
Rituais de consumo de cannabis por usuários na fronteira entre o Brasil e o Uruguai | 10

manutenção das políticas proibicionistas e coibir o comércio de Cannabis no Brasil. Isso aponta para a desestruturação do tráfico de Cannabis no Uruguai após a regulamentação do comércio e consumo, uma vez que as leis uruguaias inviabilizam o comercio legalizado para brasileiros e que os mesmos já não encontram esta substância no mercado ilegal.

O ritual de aquisição de Cannabis pelo usuário brasileiro inclui o deslocamento até os pontos de tráfico, local este em que outras substâncias psicoativas ilegais são vendidas, expondo-o à possibilidade de experimentação diversificada, quando já se conhece previamente os efeitos. Este fato contrasta com a realidade uruguaia que tem a não exposição do usuário a outras substâncias, pois o mesmo tem a possibilidade de cultivar a planta, participar de clubes de plantio ou comprar o volume de $40 \mathrm{~g}$ mensais nas farmácias do país, consequência da regulamentação do comércio e consumo de Cannabis uruguaio. ${ }^{2}$

O ritual de aquisição de Cannabis no lado brasileiro da fronteira, inclui o deslocamento, aos pontos de tráfico, levando a inserção do usuário aos ambientes de vulnerabilidade social, espaços em que há possibilidade de exposição à violência urbana ou a confrontos entre policiais e traficantes, entre outros. Já o modo de aquisição da substância no Uruguai parece ser mais seguro, pois evita o deslocamento dos usuários a espaços de violência. A Lei de Regulamentação permite a produção de Cannabis para consumo próprio, ${ }^{2}$ oferecendo maior segurança a respeito da procedência e qualidade do produto, excluindo a possibilidade da atribuição de outras substâncias desconhecidas aos insumos utilizados. ${ }^{15}$

O ritual de consumo de Cannabis na fronteira entre Brasil e Uruguai processa-se como um evento social para alguns usuários, enquanto para outros, efetiva-se de modo particular. Esta divergência parece estar relacionado à aceitação desta prática pelos grupos sociais no qual este está inserido, bem como na tentativa de obstar efeitos desagradáveis que possam surgir. Inferese que o uso em conjunto traz maior prazer ao consumo, sendo este fator condicionado a sociabilidade dos elementos que compõe o grupo. 
11 | Tavares DH, Franchini B, Biondi HS, Jardim VMR, Rodrigues CGSS, Camargo PO

A literatura revela que, quando o usuário está iniciando o consumo de Cannabis, ele precisa aprender a realizar o uso e se sentir protegido em relação aos possíveis efeitos, sendo essencial a efetivação do ritual de modo coletivo. ${ }^{16}$ A necessidade de companhia para poder realizar os rituais de uso, influencia na periodicidade deste, o que pode ser compreendido como um fator preventivo ao uso problemático. ${ }^{13} \mathrm{O}$ contexto do uso coletivo perpassa o desenvolvimento de regras e controles sociais que são estabelecidas pelo grupo.

Todavia, quando aprendem a usar e a ter o melhor aproveitamento dos efeitos da substância, muitos usuários optam por fazer o uso sozinhos. ${ }^{16}$ Infere-se que os motivos apresentados para esta escolha seriam evitar envolver-se com pessoas que façam uso de outras substâncias psicoativas, com as quais o usuário não quer ter contato ou ser incentivado ao uso, ou, ainda, para manter-se na abstinência de outras “drogas” consumidas pelos demais membros do grupo, como o Crack. Este aspecto vai de encontro ao revelado pela literatura, ${ }^{17}$ que desconsidera a capacidade do usuário de Cannabis de controlar o início do consumo de outra substância. O ritual de uso coletivo pode ser evitado para não chamar atenção da polícia, quando este se processa em ambientes públicos.

No que tange ao local da efetivação do ritual de uso de Cannabis, este parece estar ligado a aspectos relacionados com a segurança do usuário, como em outras substâncias psicoativas. Efetuar em ambientes abrigados, como a casa onde não há exposição à sociedade, revela-se como fator protetivo, que mantém o usuário em sigilo e impede a recriminação desta prática. ${ }^{17}$

Todavia, na inviabilidade de fazê-lo em local abrigado, o uso em ambientes públicos, no lado brasileiro da fronteira, se processa com ressalvas, havendo a necessidade de mantê-lo escuso. Neste sentido, aspectos ecológicos tornam-se primordiais para garantir o sigilo e a segurança, como locais menos expostos de praças e parques, perpetuando os rituais relativamente reservados. Não somente, perpassam ideais de discrição, respeito e parcimônia, que visam não incomodar ou escandalizar a sociedade. ${ }^{18}$ 
A literatura demonstra que, mesmo quando o ritual se processa em local mais sigiloso, há certo grau de exposição desta prática em virtude do aroma exalado pela combustão da Cannabis. ${ }^{18}$ Assim sendo, quando realizado em local abrigado, como a casa do usuário, há possibilidade de que pessoas vizinhas percebam a execução desta prática e acionem serviços de segurança pública. Já nos ambientes externos, a prática fica ainda mais exposta, podendo chamar a atenção de transeuntes ou da polícia. De modo geral, ao tentar manter a prática sigilosa de lado, está expondo-se a mesma por outro. ${ }^{19}$ Para evitar tal situação, realizar o ritual do lado uruguaio da fronteira revela-se como uma alternativa aos usuários brasileiros que vislumbram, neste ambiente, segurança e aceitação, mesmo sendo proibido.

Esta condição revela a falta de um debate público brasileiro e a manutenção da repetição de ideias falsas, autoritárias e preconceituosas, que desqualificam, marginalizam e demonizam o usuário, que necessitam permanecer escusos, sendo considerados um risco à sociedade. Este modo reducionista de estereotipar a pessoa usuária, garante o encobrimento de problemas estruturais da sociedade, pois enfatiza a importância deste inimigo imaginário, revelando-se necessário para o status quo. ${ }^{12}$

A prática de uso que concretiza parte do ritual de consumo na região da fronteira, acontece de modo específico para a Cannabis. As características físicas e o modo de apresentação da substância parece levar o usuário a adotar rituais uniformes, tendo destaque o consumo da substância apresentada de modo prensado, que precisa ser "esmurrugada" (esfarelada), facilitando assim sua acomodação para que o cigarro seja enrolado.

Esta prática também foi relatada em estudo anterior, ${ }^{13}$ que descreve que o ato de "esmurrugar" deixa a erva mais fina, facilitando a retirada das partes que não se deseja consumir, considerando que não há preferência por sementes e talos da erva. A substância, após sair do estado prensado, torna-se menos densa, mais expansível e maleável, facilitando a racionalização da quantidade de uso, distribuindo esta em um número equivalente possível ou almejado de cigarros. 
13 | Tavares DH, Franchini B, Biondi HS, Jardim VMR, Rodrigues CGSS, Camargo PO

Infere-se que o preparo do cigarro com papel de seda relaciona-se com as características de baixa combustibilidade, tornando mais lenta a queima do cigarro; baixa interferência no sabor em virtude da reduzida adição de corantes e outros produtos químicos à matéria de base (celulose, linho, fibra de milho, palha de arroz, dentre outros); e, resistência do papel, que garante o manuseio do cigarro sem o rompimento do mesmo. Além disso, a apresentação comercial do papel de seda para cigarros parece facilitar seu acondicionamento e transporte sem danos ao produto e de modo discreto.

A escolha pela utilização da seda para a realização do ritual ao invés de cachimbos específicos pode estar atrelado ao medo que o usuário tem da discriminação e da atuação coercitiva da polícia. Em caso de abordagem por esses profissionais, os usuários podem atribuir a posse do papel de seda ao consumo de tabaco, que é substância psicoativa lícita, diminuindo a probabilidade de sofrer sansões penais ou de ter outros problemas com o órgão de segurança.

A forma como é consumida a Cannabis, por meio de cigarros feitos com papel de seda, demonstra-se mais segura ao usuário se comparada às outras substâncias ilegais, como o Crack, que tem a lata ou cachimbos metálicos improvisados como principais recipientes de uso. ${ }^{20}$ Considera-se que o contato repetido com o alumínio aquecido pode lesar o tecido cutâneo e a mucosa oral, causando o aparecimento de bolhas e feridas nos tecidos como língua, lábios, rosto e dedos. Ao ser compartilhado este instrumento, pode haver o contato com soluções de continuidade de outros usuários, como o sangue, oriundo das lesões causadas por queimaduras, o que pode aumentar o risco de transmissão de doenças infectocontagiosas. ${ }^{17}$

A maneira como o ritual de consumo de Cannabis se processa relaciona-se diretamente com o efeito desejado. Tais aspectos consideram a farmacodinâmica e farmacocinética da substância, e revelam-se no ato de tragar e segurar a fumaça a nível pulmonar, para permitir a absorção e o transporte pela corrente sanguínea e, então, chegar ao nível de sistema nervoso central e obter-se o efeito almejado. 
A frequência que é realizado o ritual de consumo de Cannabis e a quantidade consumida estão atrelados à disponibilidade desta, a forma de apresentação da substância que está disponível e não ao desejo contínuo de obter a sensação proporcionada pelo uso. Infere-se que este aspecto revela a inexistência da fissura, descrita como a ansiedade que o indivíduo adquire devido à ausência da substância psicoativa no organismo. ${ }^{21}$

Esta característica da substância psicoativa aponta a possibilidade de estabelecer um determinado controle em relação à frequência e a necessidade do uso. Pode, ainda, permitir ao usuário o planejamento e a escolha do melhor momento para realizar a exposição aos ambientes de vulnerabilidade social para aquisição da substância, evitando momentos de tensão política ou social entre traficantes e agentes de segurança pública.

Didaticamente, as formas como se efetiva o controle sobre o consumo da substância abarca três aspectos: autocontrole, controles societários e heterocontroles. Os autocontroles correspondem aos variados graus de controle que os usuários são capazes de exercer sobre seu consumo, periodicidade, quantidade usada, forma de uso e socialização envolvidos. Estes emergem da autonomia do sujeito em desenvolver suas próprias práticas de modo a satisfazer suas necessidades. Porém, por vezes, os autocontroles acabam sendo internalizações dos controles societários e heterocontroles. ${ }^{22}$

Os controles societários compreendem as pressões informais dos grupos aos quais o usuário pertence, ${ }^{22}$ e influenciam na forma como o usuário relaciona-se com a substância e como estabelece seus rituais de consumo. Por meio destes controles, também entendidos como sanções sociais, são definidos o que é uso aceitável, os padrões de comportamentos, os meios sociais seguros, os cuidados a serem tomados antes do uso, dentre outros, condenando os elementos e ações que fogem a esse padrão. ${ }^{23}$ Incluem-se nestes, as regras estabelecidas para a efetivação do uso no que tange a escolha do local de consumo, de modo a preservar esta ação da exposição demasiada que prejudique, direta ou indiretamente, o consumo e a segurança dos demais usuários. ${ }^{18}$ 
15 | Tavares DH, Franchini B, Biondi HS, Jardim VMR, Rodrigues CGSS, Camargo PO

Já os heterocontroles compreendem as políticas, leis ou ações públicas que visam coibir, controlar ou enfrentar o consumo de substâncias psicoativas. Esta forma de controle busca sobrepor-se às outras formas, porém, embora sejam legítimas, não são capazes de resolver, nem tangencialmente, os problemas que envolvem a temática. ${ }^{22}$

Os heterocontroles e controles societários que influenciam os rituais de consumo de Cannabis do lado brasileiro da fronteira são pautados por meio de concepções que apresentam o uso como prática criminosa, carregada de estigmas sociais, levando ao autocontrole que perpassa o sigilo do ritual e o afastamento dos serviços que possam apregoar discursos e ações criminilizatórias. De maneira oposta, os heterocontroles e controles societários estabelecidos do lado uruguaio da fronteira, perpassam a possibilidade da não exclusão social do usuário de Cannabis e do estabelecimento autocontroles que incluem a participação dos profissionais de saúde, dentre outros agentes. Desta perspectiva, emerge a possibilidade de ações terapêuticas efetivas voltadas à saúde coletiva, como o emprego da estratégia de Redução de Danos, visando à substituição de substâncias psicoativas pesadas pelas leves, como a Cannabis.

As sensações proporcionadas pelo ritual de consumo de Cannabis mostrou-se heterogenia, aspecto este encontrado na literatura, ${ }^{16}$ sendo que estas sensações sofrem interferência das experiências singulares e concretas de cada sujeito. ${ }^{13}$ As distintas sensações também foram descritas em outro estudo, ${ }^{13}$ apontando que há uma variedade destas, e que essas podem ser positivas e prazerosas, ou negativas, indiferentes, decepcionantes e pouco prazerosas.

A literatura, na atualidade, busca consolidar o conhecimento em relação às sensações trazidas pelo uso da Cannabis, por meio dos seus efeitos terapêticos, demonstrando que a mesma é capaz de proporcionar efeitos ansiolíticos, estimular apetite, além de efeitos antieméticos, relaxantes e analgésicos para dores crônicas e agudas. Diante desta gama de efeitos benéficos, emerge a possibilidade do uso da Cannabis nos tratamentos para patologias como Vírus da Imunodeficiência Humana, depressão, Câncer, epilepsia, dentre outras. ${ }^{24}$ 
Rituais de consumo de cannabis por usuários na fronteira entre o Brasil e o Uruguai | 16

As divergências relatadas no que tange as sensações podem ser atribuídas a dois aspectos: características dos usuários e características da Cannabis. Em relação aos usuários, destacam-se os elementos relacionados às necessidades emocionais, socialização e afetividade, bem como características da personalidade e psicossociais.

Já as características da Cannabis que interferem em seus efeitos, destacam-se as diferentes formas de apresentação, espécies e partes da planta, as características físico-químicas variadas, com diferentes concentrações de THC (princípio ativo da Cannabis) o que pode interferir nas sensações. Cabe destacar que, em virtude da ilegalidade da produção, comércio e consumo no Brasil, podem ser aditivadas a Cannabis outras substâncias desconhecidas e não desejáveis pelos consumidores.

A adição de outros substratos a Cannabis pode ocorrer com a intenção de ampliar o rendimento da planta em comparação à sua forma pura, visando proporcionar maior lucratividade ao comércio ilegal. Tal prática pode levar os usuários a consumirem outras substâncias potencialmente nocivas a saúde, e que não proporcionam as sensações almejadas.

Cabe destacar que a temática aqui discutida não pode ser dissociada do contexto social. Não obstante, permanecem pouco clarificados os aspectos referentes à disponibilidade da droga, considerações mercadológicas, as tendências, as regras e padronizações sociais, os valores, a estrutura de vida dos usuários, dentre outros, que também influenciam o consumo de qualquer substância psicoativa, como revela a literatura. ${ }^{25}$

\section{Considerações finais}

Através deste estudo foi possível conhecer os aspectos que permeiam o ritual de consumo de Cannabis por usuários na fronteira do Brasil com o Uruguai, tais como as influências da fronteira sobre o consumo de Cannabis, socialização entre usuários brasileiros e uruguaios, ambientes propícios para o consumo e aspectos específicos da fronteira que influenciam a prática de uso. 
17 | Tavares DH, Franchini B, Biondi HS, Jardim VMR, Rodrigues CGSS, Camargo PO

Dessa forma, o ritual está atrelado às características pessoais do usuário, dos grupos sociais e do território em que ele o realiza, destacando-se as influências conflitantes das políticas públicas existentes entre os dois países. A confluência das leis sobre drogas dos dois países em questão, podem interferir nas formas de aquisição da substância, na socialização, efetivação de uso, na escolha dos locais, na frequência e periodicidade do consumo, e nas sensações experienciadas pelos usuários.

Como limitação do estudo, observa-se a uniformidade amostral dos participantes alcançados pelo método bola de neve, que pode reduzir o contraste de perspectivas destes indivíduos em relação aos rituais de consumo de Cannabis na região da fronteira entre Brasil e Uruguai. Todavia, o método de coleta de dados justifica-se devido a dificuldade de acesso e abordagem as pessoas usuárias de Cannabis.

Considerando a interface Brasil-Uruguai existente neste espaço de fronteira e da regulamentação deste último país em relação à cadeia de produção de Cannabis, considera-se que mudanças nos rituais de consumo estão continuamente acontecendo, sendo necessário o acompanhamento das transformações sociais neste espaço ambivalente. Diante do exposto, sugere-se novas pesquisas de modo a descortinar as nuances sociais e políticas envolvidas, vislumbrando um debate contínuo e amplo sobre a temática.

\section{Referências}

1. Global Comission on Drug Policy. Sob controle: caminhos para políticas de drogas que funcionam [Internet]. 2014 [acesso em 2017 fev 12]. Disponível em: https:/www.globalcommissionondrugs.org/wpcontent/uploads/2016/03/GCDP_2014_taking-control_PT.pdf

2. Republica Oriental del Uruguay. Instituto de Regulação e Regulação de Cannabis do Uruguai (IRCCA). Junta Nacional de Drogas. Control y Regulación del mercado de Cannabis: Ley 19172 y decretos regulamentarios [Internet]. Montevideo; 2013 [acesso em 2016 dez 05]. Disponível em: https://www.ircca.gub.uy/wp-content/uploads/2019/06/Ley19172-Decretos-ingles-espanol.pdf

3. Ferrari M. As noções de fronteira em geografia. Perspect Geogr [Internet]. 2014 [acesso em 2016 out 28];9(10):1-25. Disponível em: http://e-revista.unioeste.br/index.php/pgeografica/article/view/10161/7550 
4. Peirano M. Etnografia e rituais: relato de um percurso. Anu Antropol [Internet]. 2016 [acesso em 2017 fev 10];41:237-48. Disponível em: http://www.dan.unb.br/images/pdf/anuario_antropologico/Separatas_2015-1_julho2016/Etnografia_e_Rituais.pdf

5. Canclini GN. El consumo cultural: una propuesta teórica. In: Sunkel G. El consumo cultural en América Latina. Construcción teórica y líneas de investigación. 2ª ed. ampliada y revisada. Bogotá: Convenio Andrés Belo; 2006.

6. Brasil. Ministério do Planejamento, Desenvolvimento e Gestão. Instituto de Pesquisa Econômica Aplicada. O consumo de drogas e a saúde pública na zona de fronteira entre Brasil e Uruguai: resultados qualitativos. Brasília (DF): IPEA; 2017 [acesso em 2017 fev 07]. Disponível em: http://www.ipea.gov.br/portal/images/stories/PDFs/relatoriopesquisa/170706_relatorio_pesquisa_consum o_drogas_saude_publica_zona_fronteira_brasil_uruguai.PDF

7. Cardano M. Manual de pesquisa qualitativa: a contribuição da teoria da argumentação. Petrópolis (RJ): Vozes; 2017.

8. Waters J. Snowball sampling: a cautionary tale involving a study of older drug users. Int J Soc Res Methodol [Internet]. 2015 [acesso em 2018 fev 05];18(2):367-80. Disponível em: http://www.tandfonline.com/doi/abs/10.1080/13645579.2014.953316?tab=permissions\&scroll=top

9. Bardin L. Análise de conteúdo. São Paulo: Edições 70; 2013.

10. Mynaio MCS. Amostragem e saturação em pesquisa qualitativa: consensos e controvérsias. Rev Pesq Quali [Internet]. 2017 [acesso em 2017 fev 07];5(7):01-12. Disponível em: https://edisciplinas.usp.br/pluginfile.php/4111455/mod_resource/content/1/Minayosaturacao.pdf

11. Brasil. Ministério da Saúde. Conselho Nacional de Saúde. Resolução n. 466, de 12 de dezembro de 2012. Aprova as diretrizes e normas regulamentadoras de pesquisas envolvendo seres humanos. Diário Oficial da União. Brasília (DF); 2013 jun 13; Seção 1, p. 59-62.

12. Macrae EJBN. Antropologia: aspectos sociais, culturais e ritualísticos. In: Seibel SD, organizador. Dependência de drogas. São Paulo: Atheneu; 2010.

13. Macrae EJBN, Simões JA. A subcultura da maconha, seus valores e rituais entre setores socialmente integrados. In: Macrae EJBN, Alves WC, organizadores. Fumo de Angola: Cannabis, racismo, resistência cultural e espiritualidade. Salvador: EDUFBA; 2016.

14. Pacheco MEAG, Andrade JD. Concepções em redução de danos no projeto consultório de rua: práticas na saúde mental. INTERThesis [Internet]. 2017 maio [acesso em 2017 fev 07]14(2):5774.Disponível em: https://periodicos.ufsc.br/index.php/interthesis/article/view/1807-1384.2017v14n2p57

15. Alcântara LTA. Adulterantes encontrados em drogas ilícitas: uma abordagem forense. Acta Ciênc Saúde [Internet]. 2016 [acesso em 2017 fev 07];5(2):1-16. Disponível em: http://www2.ls.edu.br/actacs/index.php/ACTA/article/view/129/120 
16. Becker HS. Outsiders: studi di sociologia della devianza. Milão (Itália): Meltemi; 2017.

17. Jorge MSB, Quinderé PHD, Yasui S, Albuquerque RA. Ritual de consumo do crack: aspectos socioantropológicos e repercussões para a saúde dos usuários. Ciênc Saúde Colet [Internet]. 2013 out [acesso em 2017 fev 25];18(10):2909-18. Disponível em:

http://www.scielo.br/scielo.php?script=sci_arttext\&pid=S1413-81232013001000015

18. Veríssimo M. As rodas culturais e a "legalização” da maconha no Rio de Janeiro. Ponto Urbe [Internet]. 2015 [acesso em 2017 abr 02]; Disponível em: http://pontourbe.revues.org/2682

19. Policarpo F, Veríssimo M, Figueiredo E. A fumaça do bom direito? Demandas pelo acesso legal à maconha da cidade do Rio de Janeiro. Platô Drogas Políti [Internet]. 2017 [acesso em 2017 fev 07]1(1):1337. Disponível em: http://pbpd.org.br/wp-content/uploads/2016/11/PLATO-.compressed-1.pdf

20 Ferreira RZ, Oliveira MM, Kantorski LP, Coimbra VCC, Jardim VMR.A teoria dos dons e dádivas entre grupos de usuários de crack e outras drogas. Texto\& contexto enferm [Internet]. 2015 Jun [acesso em $2017 \quad$ mar 19$] ; 24(2): 467-75 . \quad$ Disponível em:http://www.scielo.br/scielo.php?script=sci_arttext\&pid=S010407072015000200467\&lng=en\&nrm=iso\&tlng=pt

21. Teixeira MB, Engstrom EM, Ribeiro JM. Revisão sistemática da literatura sobre crack: análise do seu uso prejudicial nas dimensões individual e contextual. Saúde Debate [Internet]. 2017 mar [acesso em 2017 fev 02];41(112):311-30. Disponível em: http://www.scielo.br/scielo.php?script=sci_arttext\&pid=S0103$11042017000100311 \& \operatorname{lng}=$ en

22. Castel R, Coppel A. Lescontrôles de latoxicomanie. In: Ehrenberg A, organizador. Individus Sous Influence. Paris: Éditions Esprit; 1991.

23. Acioli Neto ML, Santos MFS. Os Usos de crack em um contexto de vulnerabilidade: representações e práticas sociais entre usuários. Psic Teor Pesq [Internet]. 2016 [acesso em 2017 fev 02];32(3):1-9. Disponível em: http://www.scielo.br/scielo.php?script=sci_arttext\&pid=S0102$37722016000300205 \& \operatorname{lng}=\mathrm{en} \& \mathrm{nrm}=$ iso

24. Ascenção MD, Lustosa VR, Silva LJ.Canabinoides no tratamento da dor crônica. Rev Med Saúde Brasília [Internet]. 2016 [acesso em 2017 jan 20];5(3):255-63. Disponível em:

https://portalrevistas.ucb.br/index.php/rmsbr/article/view/7009

25. Acioli Neto ML, Santos MFS. As máscaras da pobreza: o crack como mecanismos de exclusão social. Psicol Estud [Internet]. 2016 maio [acesso em 2017 jan 28];20(4) 611-23. Disponível em: http://www.periodicos.uem.br/ojs/index.php/PsicolEstud/article/view/28292/pdf

\section{Autor correspondente}

Diogo Henrique Tavares

E-mail: enf.diogotavares@gmail.com

Endereço: Avenida Duque de Caxias, 336. Pelotas, Rio Grande do Sul, Brasil.

CEP: $96030-000$ 


\section{Contribuições de Autoria}

1 - Diogo Henrique Tavares

Participou da concepção e o delineamento da pesquisa, análise e interpretação dos dados, redação do artigo e aprovação da versão a ser publicada.

2 - Beatriz Franchini

Participou da concepção e o delineamento da pesquisa;

3 - Heitor Silva Biondi

Participou da análise e interpretação dos dados, redação do artigo e aprovação da versão a ser publicada;

4 - Vanda Maria da Rosa Jardim

Participou da revisão crítica e aprovação da versão a ser publicada;

5 - Cândida Garcia Sinott Silveira Rodrigues

Participou da revisão crítica e aprovação da versão a ser publicada;

6 - Paola de Oliveira Camargo

Participou da revisão crítica e aprovação da versão a ser publicada;

\section{Como citar este artigo}

Tavares DH, Franchini B, Biondi HS, Jardim VMR, Rodrigues CGSS, Camargo PO. Rituais de consumo de cannabis por usuários na fronteira entre o Brasil e o Uruguai. Rev. Enferm. UFSM. 2019 [Acesso em: 2019 jun 15];vol ex:p1-p20. DOI:https://doi.org/10.5902/2179769230956 